\title{
Lung CT Scan
}

\author{
Paolo Pelosi.".1 and Marcelo Gama de Abreu ${ }^{2}$
}

\author{
${ }^{I}$ Department of Ambient, Health and Safety, University of Insubria, Varese, Italy \\ ${ }^{2}$ Pulmonary Engineering Group, Department of Anesthesiology and Intensive Care Therapy, University Hospital Carl \\ Gustav Carus, Dresden, Germany
}

\begin{abstract}
In the last 20 years, the use of computed tomography (CT) to evaluate thoracic diseases has rapidly gained popularity and CT has become firmly established as an important research and diagnostic modality. In particular, CT has played an important role in improving our knowledge about the pathophysiology of the adult respiratory distress syndrome (ARDS) and in determining the morphological and functional relationships of different therapeutic options commonly used in the clinical management of this syndrome. CT scan may provide: 1) accurate measurement of the impact of mechanical ventilation on hyperaeration and reaeration/recruitment, being the most objective technique currently available to set mechanical ventilation and identifying patients for extracorporeal lung support; 2) the amount of lung edema, associated with the severity of the alveolar capillary barrier lesion and the risk of mortality; 3) clinical information in patients with a sudden and unexplained deterioration of the clinical status or the lack of expected improvement as well as to follow the evolution with time. We recommend to perform: 1) one single whole lung CT scan at end-expiration at PEEP $5 \mathrm{cmH}_{2} \mathrm{O}$, to evaluate the distribution of aeration and to compute the amount of lung weight; 2) only three lung CT slices, taken at the lung apex, hilum, and basis, at PEEP $=5 \mathrm{cmH}_{2} \mathrm{O}$ and at Pplat $=45 \mathrm{cmH}_{2} \mathrm{O}$, to assess of lung recruitability; 3) a CT scan as early as possible after onset of ARDS (if clinical characteristics persist for more than 24 hours) and repeat it after 1 week if no clinical improvement is observed; 4) a CT scan in presence of any clinical deterioration not explained by conventional diagnostic tools. We suggest considering the measurement of extravascular lung water and end-expiratory lung volume by non radiological techniques and lung ultrasound if CT scan cannot be done.
\end{abstract}

Keywords: Computed tomography, acute respiratory distress syndrome, lung recruitment, positive end-expiratory pressure, lung edema.

\section{INTRODUCTION}

In the last 20 years, the use of computed tomography (CT) to evaluate thoracic diseases has rapidly gained popularity and CT has become firmly established as an important research and diagnostic modality. In fact, CT makes it possible to obtain cross-sectional imaging of the lung, so that virtually all intrathoracic pathological conditions can be evaluated. In particular, CT has played an important role in improving our knowledge about the pathophysiology of the adult respiratory distress syndrome (ARDS) and in determining the morphological and functional relationships of different therapeutic options commonly used in the clinical management of this syndrome [1-5]. ARDS refers to a generalized inflammation of the lung parenchyma, caused by different diseases. This syndrome is characterized by diffuse pulmonary infiltrates, decreased respiratory compliance and severe hypoxemia, barely responsive to the administration of high inspiratory oxygen concentrations $[6,7]$. Moreover, the pathological characteristics of ARDS may change during the course of the disease, from edema to fibrosis and disruption of alveolar septa [7]. Although important advances have been made in the understanding of the epidemiology, natural history, and

*Address correspondence to this author at the Department of Ambient, Health and Safety, University of Insubria, Varese, Italy; Tel: 0039-0332421435; Fax: 0039-0332-421390; E-mail: ppelosi@hotmail.com pathogenesis of the disease, leading to the design and testing of new treatments, mortality due to this syndrome remains extremely high [8].

The purpose of this review is to briefly summarize the role of CT in defining the pathophysiology of the ARDS lung and the possible therapeutic, clinical implications of these findings. In particular we will discuss: 1) the technical aspects of CT when applied to the lung parenchyma; 2) the role of CT in defining the pathophysiology of the ARDS in experimental and clinical studies and 3) the usefulness of CT in clinical practice.

\section{TECHNICAL ASPECTS}

\section{Quantifying Gas/Tissue Ratio}

In the past, $\mathrm{CT}$ scans have been mainly used to depict anatomic abnormalities. However, CT scans can also deliver information about the quantitative relationship between gas and tissue.

CT scans are able to produce digital images consisting of a matrix of picture elements, called pixels. Since the matrix has not only the dimensions of height and width, but also depth, pixels in the matrix represent voxels, i.e., volume elements that attenuate the radiation of the CT scanner crossing them, according to their physical properties. The attenuation of the X-ray energy crossing the voxels, summarized in the $\mathrm{CT}$ number, is determined by different 
factors, including the X-ray energy itself, the atomic number of the substance and the density. Since the attenuation due to the interaction of the X-ray with the substance (tissue) can be minimized, the CT number is closely related to the density of the voxel. CT numbers are referenced to distilled water, which has been assigned a value of zero. The unit of the CT number scale is Hounsfield Unit (HU) due to the pioneer contribution of Sir Godfrey Newbold Hounsfield to the development of CT scan. Accordingly, distilled water has a $\mathrm{CT}$ number equal to $0 \mathrm{HU}$. In order to depict a wide range of densities and assuming a linear relationship between attenuation and density, a scale factor of 1000 multiplies the relative density of the material $x$, according to Eq. (1):

$$
\text { CT number }=\frac{\mu_{x}-\mu_{\mathrm{H}_{2} \mathrm{O}}}{\mu_{\mathrm{H}_{2} \mathrm{O}}} \times 1000
$$

where $\mu_{\mathrm{H}_{2} \mathrm{O}}$ is the attenuation coefficient of water. By convention, air has been assigned a value of $-1000 \mathrm{HU}$, while bone has a CT number of $+1000 \mathrm{HU}$. Assuming that tissue has the same density as water and that lung gas has the same density as air, Eq. 1 can be rearranged to yield the gas/tissue volume relationship in the voxel $i$, as shown in Eq. 2:

volume of gas $_{i} /\left({\text { volume of } \text { gas }_{i}+\text { volume of tissue }}_{i}\right)=$

\section{CT number $/$ / 1000}

According to Eq. 2, a voxel with a CT number of -500 HU has $50 \%$ of its volume corresponding to gas, while the other $50 \%$ is tissue. However, the distribution of gas and tissue within the voxel and the nature of the "tissue" part of the voxel remain unknown. In other words, CT numbers do not permit to distinguish between collapsed tissue and flooding.

Since the volume of the voxel is known, Eq. 2 also allows us to determine gas and tissue volumes. Rearranging Eq. 2 leads to:

volume of tissue $_{i}=\left(1+\frac{\text { CT number }}{i}\right) \times$ volume $_{i}$

The total gas and tissue volumes of the lungs can be computed by simply adding the respective volumes in all voxels containing lung parenchyma, i.e., in the so-called region of interest (ROI). Since volume $e_{i}$ is constant, the total tissue volume is given by:

total volume of tissue $=$

$\left(1+\frac{\text { mean } C T \text { number }}{1000}\right) \times$ total lung volume

If we assume that the density of tissue is $1 \mathrm{~g} / \mathrm{cm}^{3}$, i.e. the same as distilled water, the total lung mass can be also calculated from the mean $\mathrm{CT}$ number and the total lung volume. It is important to note that in Eqs. 2 to $4, \mathrm{CT}$ numbers $>0$, i.e. representing voxels with density higher than that of water, are made equal to zero. This procedure is necessary, because the attenuation of lung tissue, which may contain cells and proteins, is slightly higher than that of water. However, such voxels usually represent less than $2 \%$ of total.

Due to the high spatial resolution of the CT scanners, the calculation of volume and mass previously shown can also be applied to different regions of lungs. Typically, the lungs have been divided into gravitation-dependent zones in lying individuals (coronal planes), and calculations performed in iso-gravitational slices. Fig. (1) shows the frequency of CT numbers in a CT scan of a pig with acute lung injury (ALI) induced by surfactant depletion. Analysis was performed in 3 zones along the cranial-caudal axis and showed a shift from left to right of the distribution curves along the ventralto-dorsal gradient, which is related to a loss of aeration.

\section{Aeration Compartments}

Independent on the anatomical position of the voxels, they can be grouped into so-called aeration compartments if their gas content is within certain arbitrary ranges. As explained before, a voxel with a CT number $=-500 \mathrm{HU}$ has $50 \%$ of gas and $50 \%$ of tissue. Since in normal lungs $70-80 \%$ of the tissue is in the range of -500 to $-900 \mathrm{HU}$, this range has been assigned to the normally aerated compartment. Accordingly, the range -100 to $-500 \mathrm{HU}$ has been related to the poorly aerated compartment, while values between +100 and $-100 \mathrm{HU}$ represent the non aerated compartment, i.e. lung tissue with less than $10 \%$ of gas content. When the voxel has more than $90 \%$ of gas, i.e. excess of gas in relation to tissue $(-900$ to $-1000 \mathrm{HU})$, it is hyperaerated. These cutoff values are not definitive and other ranges have been proposed, specially for hyperaeration [9]. However, most groups have used the ranges proposed by Rouby and Gattinoni groups, including ours.

Fig. (2) illustrates the distribution of aeration compartments in a pig with ALI induced by surfactant depletion. Although aeration compartments do show an anatomical dependency, pixels with similar gas content are distributed across different lung regions. When several CT scans are taken together, as for example during helical CT scans, three-dimensional representations of the aeration can be obtained, as shown in Fig. (3).

Although it is easier to visualize aeration compartments in terms of absolute or relative volumes, some authors prefer to quantify such compartments from their mass $[10,11]$. It has been claimed that it is not the lung volume that is exposed to aeration, but rather the lung mass. Hyperaeration or collapse more closely affects the lung mass than the volume. Accordingly, tidal hyperaeration calculated in terms of volume may suggest that higher amounts of tissue are undergoing increased aeration, while only a relatively small amount of lung tissue is involved. This difference must be taken into account when investigating the relationship between CT scans and effects of interventions. However, in our experience, when tracking the effects of ventilation manoeuvres on aeration compartments, volume and mass have fairly the same value [12].

\section{Tidal Hyperaeration, Recruitment and Reaeration}

CT scans do allow inferring the effective pressure exerted on the voxels and, therefore, transpulmonary 


\section{ZONE 1}

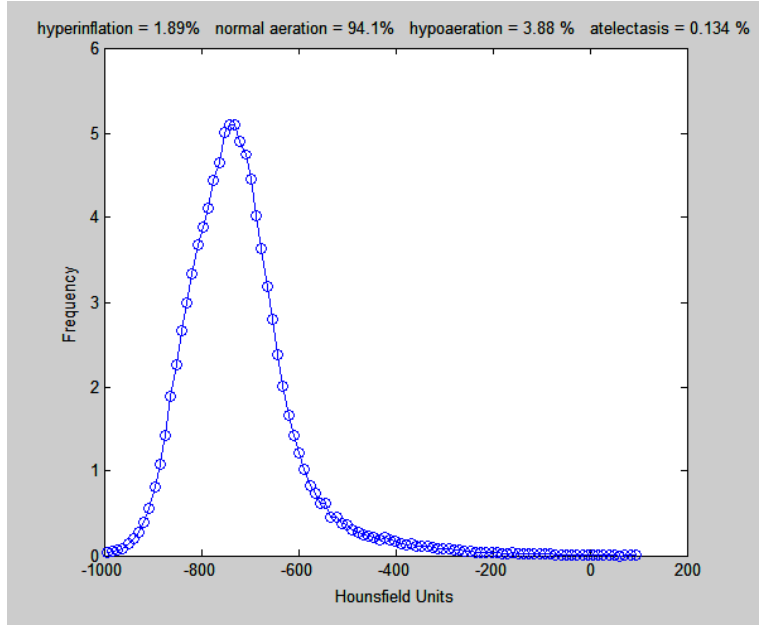

ZONE 2

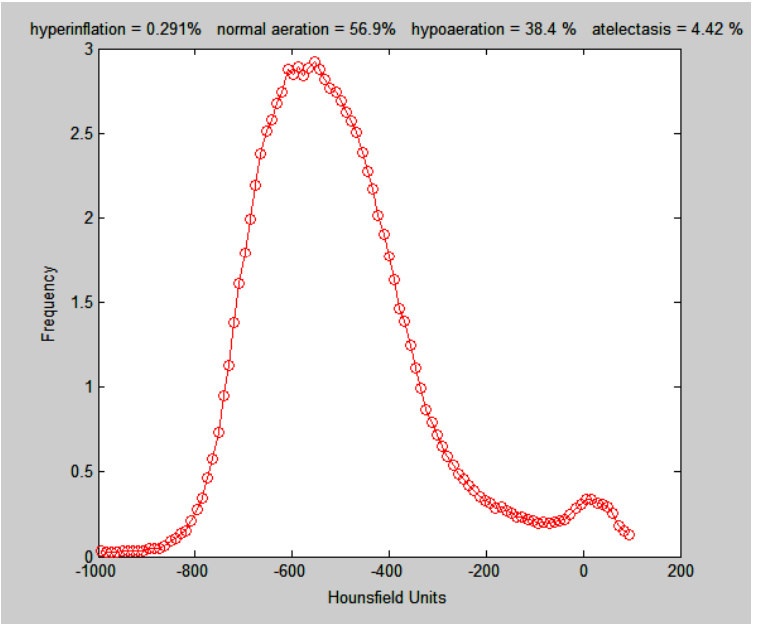

ZONE 3

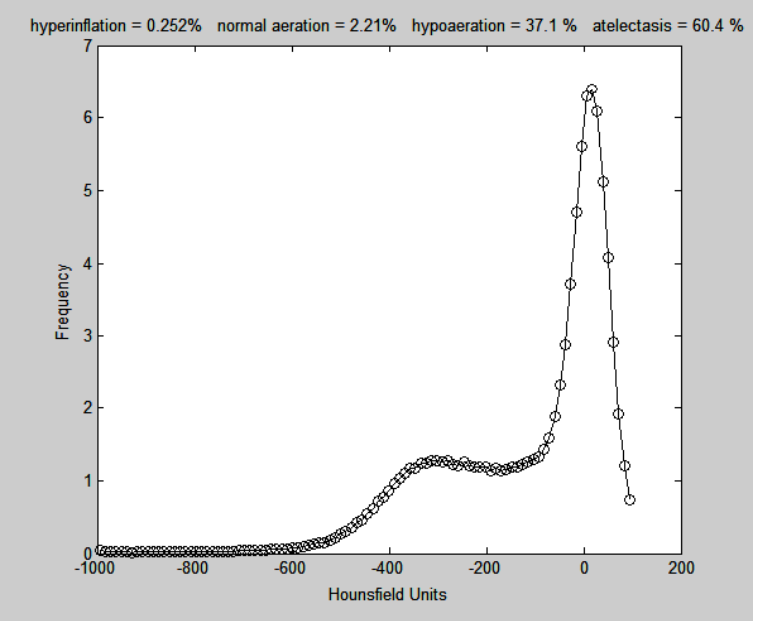

Fig. (1). Distribution of aeration in 3 iso-gravitational planes in a surfactant depletion model of lung injury. Zones 1 (blue), 2 (red) and 3 (black) correspond to non-dependent, intermediary and dependent lung zones of animal with acute lung injury in supine position. 
pressures cannot be assessed with this technique. However, during breath holds pressures are assumed to be comparable across the lungs. Thus, changes in local gas volumes can be used to determine local elastance properties provided the intrapleural pressure can be estimated.

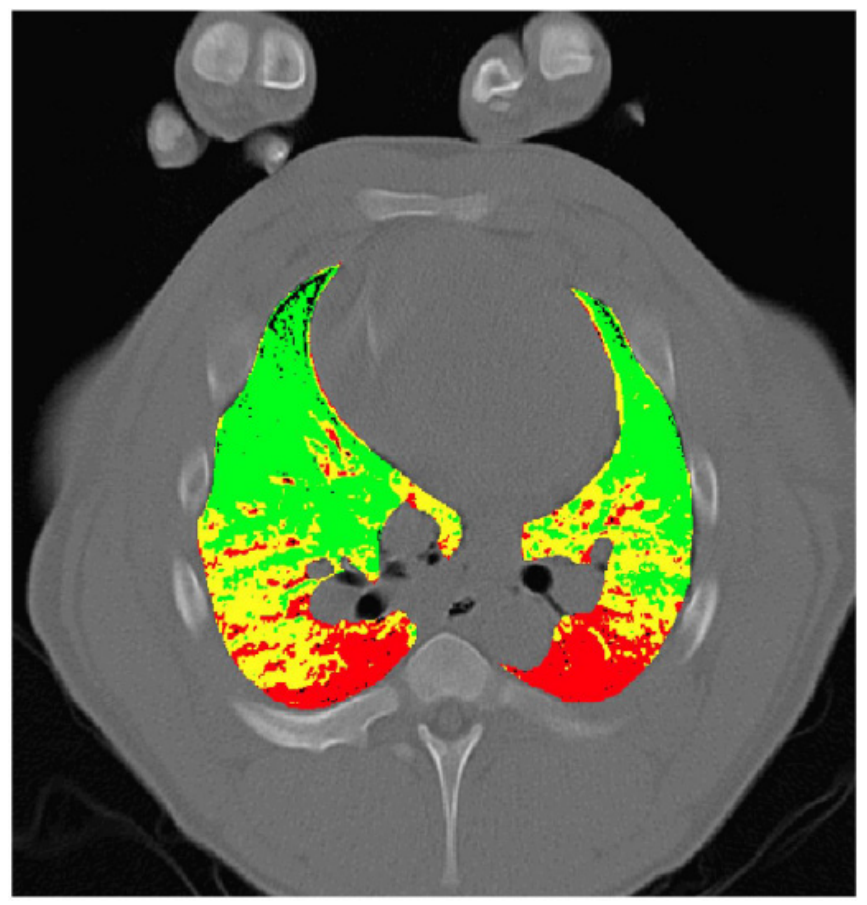

Fig. (2). Colour map of aeration compartments in a computed tomography scan obtained in model of acute lung injury in pig. Red represents non-aeration ( -100 to +100 Hounsfield Units - HU), yellow represents poor aeration (-100 to $-500 \mathrm{HU})$, green represents normal aeration (-900 to $-500 \mathrm{HU})$, black represents hyperaeration $(-1000$ to $-900 \mathrm{HU})$.

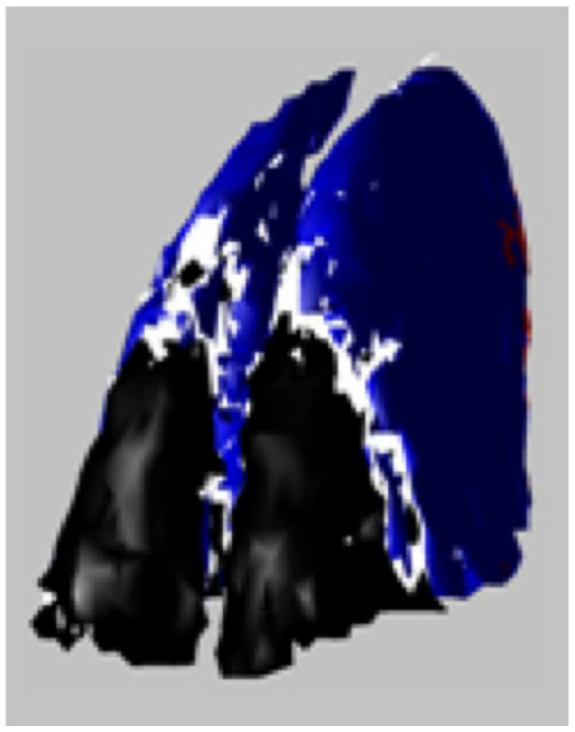

Fig. (3). Three dimensional representation of aeration compartments obtained with helical computed tomography in a surfactant depletion model of lung injury in pig (dorsal view). Black represents non-aeration ( -100 to +100 Hounsfield Units $\mathrm{HU})$, white represents poor aeration (-100 to $-500 \mathrm{HU})$, blue represents normal aeration (-900 to $-500 \mathrm{HU})$, red represents hyperaeration (-1000 to $-900 \mathrm{HU})$.
Hyperaeration is related to gas/tissue relationship and not to strain. Accordingly, patients suffering from emphysema usually show increased amounts of hyperaerated tissue, but no overdistension of tissue [2]. Overdistension may occur in regions that are normally aerated if alveolar flooding and/or interstitial oedema is present [3]. Despite these limitations, in ALI tidal hyperaeration has shown close correlation with overdistension, as evidenced from simultaneous assessment of respiratory mechanics [13-15]. Also, changes in aeration status of non-aerated and poorly aerated regions have been used to track tidal reaeation and/or recruitment in the lungs $[10,15]$, which may promote lung injury [16]. Tidal hyperaeration represents the penetration of excess of gas compared to lung tissue at end-inspiration, and is calculated as the change in the volume or mass of the hyperaerated compartment between end-inspiration and end-expiration, as shown in Eq. (5).

tidal hyperaeration $=$

( $_{\text {ypperaeration }}$ end-ins - hyperaeration $_{\text {end-exp }}$ )

Tidal recruitment represents the degree of penetration of gas in previously nonaeaerated lung tissue, and is calculated as the change in non-aerated volume or tissue between endexpiration and end-inspiration:

tidal recruitment $=\left(\right.$ nonaeration $_{\text {end }-\exp }-$ nonaeration $\left._{\text {end-ins }}\right)$

Some researchers also normalize such measurements according to the volume or mass of the normally aerated compartment at end-expiration, as shown in Eqs. (7) and (8), respectively:

norm tidal hyperaeration $=$

$\underline{\left(\text { hyperaeration }_{\text {end-ins }}-\text { hyperaeration }_{\text {end- } \mathrm{exp}}\right)}$

normal aeration $_{\text {end-exp }}$

norm tidal recruitment $=$

$\frac{\left(\text { nonaeration }_{\text {end-exp }}-\text { nonaeration }_{\text {end-ins }}\right)}{\text { normal aeration }_{\text {end }-\exp }}$

where norm represents the respective normalized compartment.

It has been claimed that alveolar recruitment may also occur in the poorly aerated compartment [17], an effect that is not taken into account if only the nonaerated compartment is considered in the calculations. Therefore, some authors [3, 17] calculated tidal reaeration instead of recruitment, as shown in Eq. (9):

\section{tidal reaeration $=$}

poorly aeration $_{\text {end-exp }}+$ nonaeration $_{\text {end }-\mathrm{exp}}$

$-\left(\right.$ poorly aeration $_{\text {end-ins }}+$ nonaeration $\left._{\text {end-ins }}\right)$

which can be also normalized to normal aeration at endexpiration.

Since all aeration compartments are usually present not only in the whole lungs but even in one single CT slice, the phenomena of tidal hyperaeration and reaeration (or recruitment) occur simultaneously in ALI/ARDS, and the 


\section{PEEP $=6 \mathrm{cmH}_{2} \mathrm{O}$}

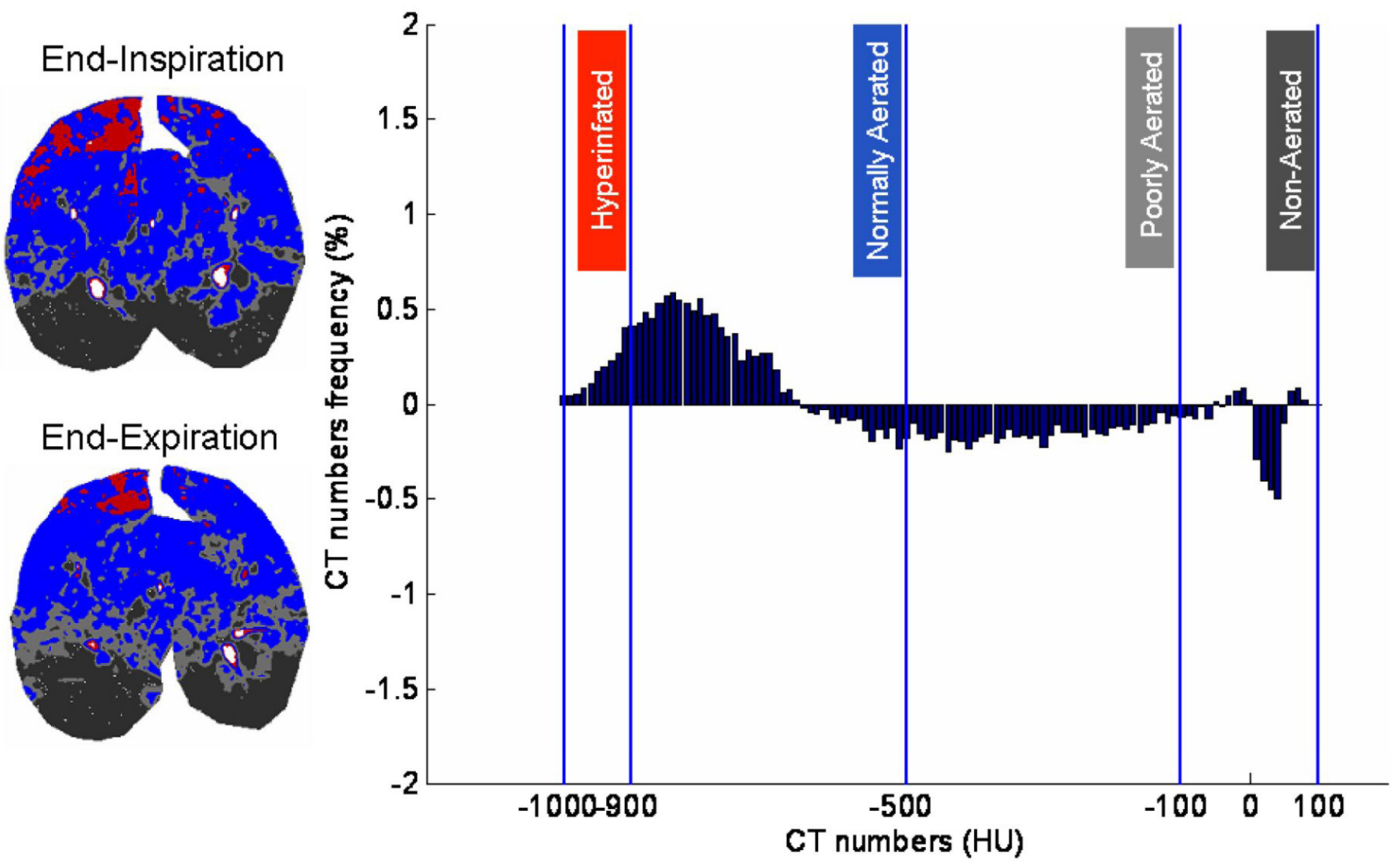

Fig. (4). Left: Colour maps of aeration compartments at end-expiration and end-inspiration in the juxta-diaphragmatic region of a surfactant depletion model of lung injury in pig; right: changes in the distribution of CT numbers between end-expiration and end-inspiration in that slice. Note the increase in the frequency of hyperinflated (hyperaerated) tissue, evidencing tidal hyperaeration, and decrease in the frequency of poorly and nonaerated tissue, evidencing tidal reaeration. Dark grey represents non-aeration (-100 to $+100 \mathrm{HU})$, light grey represents poor aeration (-100 to $-500 \mathrm{HU})$, blue represents normal aeration $(-900$ to $-500 \mathrm{HU})$, red represents hyperaeration $(-1000$ to $-900 \mathrm{HU})$.

respective proportions depend on the pressure at which measurements are performed. Fig. (4) shows the concomittent occurrence of tidal hyperaeration and reaeration in one CT scan in a pig with ALI induced by surfactant depletion.

\section{Single Slice vs Whole Lung Computed Tomography}

Calculations described so far in this chapter are applied to single CT scan slices, which can be reconstructed from the most cranial to the most caudal parts of the lungs to yield whole lung CT values. Cumulative exposure to X-ray radiation from $\mathrm{CT}$ scans has been associated with increased risk of cancer [18]. Also it was not before the 1990s that helicoidal CT scanners became available. Thus, investigators have suggested to limit the CT scans to only one slice at the juxtadiaphragmatic level, one to three slices at the apex, hilus and juxtadiaphragmatic levels [19, 20]. Apparently, both the one and the three-slice approaches seem to yield similar distribution of CT densities in patients with ALI/ARDS [21]. However, extrapolations of the findings of a few CT slices to the whole lungs may be inaccurate. Lu et al. [22] showed that both the one and the three slice methods lead to an overestimation of PEEP-induced recruitment in most patients with ALI/ARDS. This fact has been attributed to an inhomogeneous distribution of pressures across the lungs, as well as overrepresentation of the more recruitable upper lobes in apex and hilus CT scan slices. On the other hand, a single CT scan slice taken at the juxtadiaphragmatic region may result in underestimation of PEEP-induced recruitment [3]. Accordingly, estimation of tidal hyperaeration with only a few slices may also be inaccurate, since in ALI/ARDS hyperaeration is more pronounced in caudal lung regions [13].

In view of these facts, accurate measurement of the impact of mechanical ventilation on hyperaeration and reaeration/recruitment requires assessment of the whole lungs.

\section{Static vs Dynamic Computed Tomography}

CT scanning of whole lungs is usually performed at endexpiration and/or end-inspiration under breath holding and tube clamping. Alternatively, a continuous pressure can be maintained by the mechanical ventilator at the airways. Indeed, such procedure may be preferable to avoid loss of volume due to air compression and tubing leakage.

Although current CT technology allows performing helical CT of the whole lungs in 10-20 $\mathrm{s}$ and exposure to 
radiation has been importantly reduced in new generation CT devices, breath holding may introduce artefacts into the images in the presence of spontaneous breathing activity. Generation of negative pressures by the respiratory muscles against a closed endotracheal tube can theoretically skew the aeration compartments and increase nonaerated tissue [23]. Also, static CT may pose difficulties to the analysis of lung aeration during irregular breathing patterns, like variable controlled ventilation and different forms of assisted spontaneous breathing.

Such limitation may be overcome by dynamic CT scanning with multiple revolutions, followed by reconstruction of single slices with temporal resolution as high as $100 \mathrm{~ms}$. Thereby, aeration may be assessed almost continuously during multiple respiratory cycles. Despite the concern of lungs movement through the CT window and the use of only a few slices, such procedure has been used by different groups $[24,25]$. In an oleic acid model of ALI, the distribution of aeration obtained with whole lung static CT and single slice CT with high temporal resolution did not differ significantly [23]. Our group has also used dynamic CT scanning to assess the dynamics of the aeration compartments with different modes of mechanical ventilation. In the 2 companion videos, changes in aeration at the juxtadiaphragmatic region of a pig with ALI induced by surfactant depletion are shown. Video 1 was obtained during pressure support ventilation, while video 2 was obtained during biphasic pressure airway pressure ventilation with superposed spontaneous breathing. The respective scale-adapted CT numbers for that slice are shown in Fig. (5), from which regional aeration and ventilation are calculated in 4 gravitational-dependent zones from ventral to dorsal.

\section{CT SCAN AND THE ARDS LUNG}

CT scan has modified our view of the ARDS and of the optimization of the ventilatory strategy [3-5, 26]. The lung in ARDS is characterized by a marked increase in lung tissue and a massive loss of aeration. The former is homogeneously distributed, with a slight predominance in the upper lobes, whereas the latter is heterogeneously distributed. The lower lobes are essentially nonaerated, whereas the upper lobes may remain normally aerated, despite a substantial increase in regional lung tissue. The overall lung volume and the cephalocaudal lung dimensions are reduced primarily at the expense of the lower lobes, which are externally compressed by the heart and abdominal content when the patient is in the supine position. Two opposite radiologic findings, corresponding to different lung morphologies, can be observed. In patients with focal CT attenuations, frontal chest radiography generally shows bilateral opacities in the lower quadrants but can remain normal, particularly when the lower lobes are entirely atelectatic. In patients with diffuse CT attenuations, the typical radiologic pattern of "white lungs" is observed. If these patients lie supine, lung volume is preserved in the upper lobes and reduced in the lower lobes, although the loss of aeration is equally distributed between the upper and lower lobes. Interstitial edema, alveolar flooding, or both, but not collapse, are present in all regions of the ARDS lung. Compression atelectasis is observed only in caudal parts of the lung, where external forces (such as cardiac weight, abdominal pressure, and pleural effusion) tend to squeeze the lower lobes. When a positive intrathoracic pressure is applied to patients with a focal ARDS, poorly aerated and nonaerated lung regions are recruited, whereas lung regions that are normally aerated at zero end-expiratory pressure tend to be rapidly overinflated, increasing the risk of ventilator induced lung injury.

\section{CT SCAN AND THE DIAGNOSIS OF ARDS}

Since its original description by Ashbaugh et al. [27], several clinical definitions of ARDS have been proposed. The key endeavor has always been to find clinical and easily measurable findings that could identify the primarily pathologic characteristics of ARDS (i.e., the highpermeability inflammatory noncardiogenic lung edema). A systematic method of assessing severity of lung injury is required to identify patients at higher risk of death, to optimize the ventilator and clinical management and for enrollment of patients with ARDS into randomized controlled trials.

Five definitions have been proposed: 1) clinically based definitions: a) the original definition of ARDS proposed by Ashbaugh et al. [27]; b) the American-European consensus conference definition [28]; c) the "Dehli" method definition [29], 2) score-based definitions: the Murray lung injury score [30], and 3) the "time" dependent definition [31].

Ashbaugh et al. [27] defined the ARDS as hypoxemia refractory to increased inspired fraction of oxygen $\left(\mathrm{FIO}_{2}\right)$, bilateral pulmonary infiltrates on chest X-ray, low compliance of the respiratory system, and increased lung weight at autopsy. The American-European Consensus Conference [28] proposed the most widely accepted and employed definition of ARDS, which relies primarily on hypoxemia $\left(\mathrm{PaO}_{2} / \mathrm{FIO}_{2}<200 \mathrm{mmHg}\right)$ and the presence of bilateral infiltrates.

The Delphi method [29] primarily relies on hypoxemia $\left(\mathrm{PaO}_{2} / \mathrm{FIO}_{2}<200 \mathrm{mmHg}\right.$ with a positive end-expiratory pressure $(\mathrm{PEEP})>10 \mathrm{~cm} \mathrm{H}_{2} \mathrm{O}$ ) and bilateral pulmonary infiltrates on chest X-ray.

Finally, a new definition has been recently suggested [31] to take into account the maintenance of severe hypoxemia at predetermined levels of PEEP and FiO2 after the first 24 hours. In this study, it was reported that patients meeting current American-European Consensus Conference ARDS criteria may have highly variable levels of lung injury and outcomes, while patients who continued to meet ARDS criteria at 24 hours had the highest risk of death. All these definitions exclude the presence of an unilateral lung injury, as well as the presence of cardiogenic edema.

The accuracy of these definitions has been recently assessed, by using as the reference the finding of diffuse alveolar damage on autopsy [32]. Although, the definition proposed by Villar et al. [31] was not evaluated, the results have been rather disappointing, resulting in a quite poor sensitivity and specificity.

The correct identification of ARDS is still an open issue, and the clinical consequences may be important. In fact, every attempt to improve survival during this syndrome by testing different ventilatory or therapeutic strategies (such as different tidal volumes, PEEP levels, different drugs, or other means) is based on randomized clinical trials that 

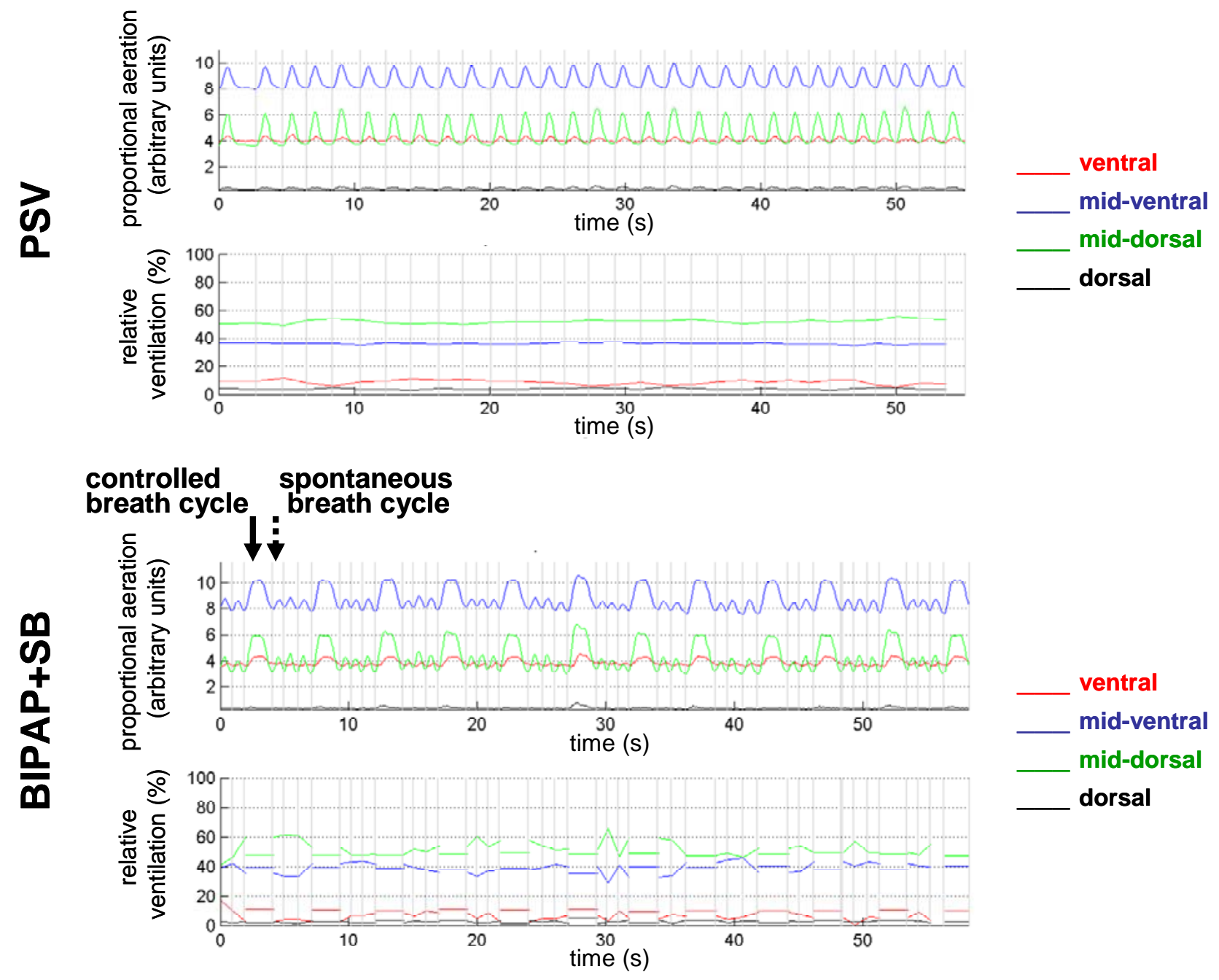

Fig. (5). Recordings of lung aeration and breath-by-breath relative ventilation in ventral (red), mid-ventral (blue), mid-dorsal (green) and dorsal (black) lung zones at the hilum during pressure support ventilation (PSV) and biphasic positive pressure + spontaneous breaths (SB) in one representative animal. Proportional aeration for a single compartment was derived from computer tomography (CT) attenuations measured in Hounsfield units and calculated as the sum of grey values of that compartment multiplied by voxel size/ $10^{6}$ (graphic representation purpose only, arbitrary units). Relative ventilation was calculated from differences in aeration at end-inspiration and endexpiration. Vertical lines in light grey demarcate end/begin of a breath cycle.

enroll patients according to a given definition. It is evident that an inappropriate definition of ARDS and a subsequent inappropriate enrolment may lead to biased results and to the rejection of techniques that might be potentially useful in ARDS patients.

Recent evidence suggests that the quantification of lung weight by $\mathrm{CT}$ scan at PEEP $5 \mathrm{cmH}_{2} \mathrm{O}$ may be extremely useful to better define those patients who are characterized by greater edema, higher alveolar collapse and higher mortality [10]. Patients with lower lung weight and recruitability (below $9 \%$ of the total lung weight, the median value of the entire ALI/ARDS population in that study) had the same lung weight as patients with unilateral pneumonia (who, by definition, are not considered to have ARDS). In contrast, higher lung weight was associated with a significantly higher recruitability (greater than 9\% of the total lung weight). If the hallmark characteristic of ARDS is lung edema (and, therefore, increased total lung weight and increased recruitability) patients with lower lung weight and lung recruitability should not be suffering from ARDS.

A novel model of ARDS has been recently proposed [33]. Most patients show an equally represented portion of core disease (the "consolidated"' lung tissue), for instance a regional pneumonia. But, in some patients, the spreading of the inflammatory reaction is limited, leading to a lower amount of lung edema and weight, lung collapse and, therefore, to a lower amount of lung recruitability. In other patients by contrast, the spreading of the inflammatory 
reaction is much greater, resulting in a more diffuse edema, an higher lung weight, an increased superimposed pressure with gravity-dependent lung collapse, and, therefore, greater lung recruitability. At the moment, it is not known why the original lung disease remains compartmentalized in some patients and why the compartmentalization of the disease is lost in others. This loss of compartmentalization may be caused by a different local balance between proinflammatory and anti-inflammatory molecular pathways or by inappropriate and injurious mechanical ventilation. Whatever the mechanisms are, we strongly believe that the definition of ARDS should be limited to patients who have higher lung weight and recruitability (i.e., to patients who have generalized noncompartmentalized inflammatory lung edema). Mortality at discharge from ICU was significantly associated with the extent of the inflammatory reaction, lung weight and recruitability and not with the amount of core disease.

In conclusion, the quantitative analysis of the lung weight by mean of a CT scan performed at PEEP $5 \mathrm{~cm} \mathrm{H}_{2} \mathrm{O}$ at endexpiration may provide information about the amount of lung edema, the severity of the alveolar capillary barrier lesion and the risk of mortality.

\section{CT SCAN IN PRIMARY AND SECONDARY ARDS}

Pathophysiology is quite different whether ARDS results from a direct (pulmonary, ARDSp) or an indirect (extrapulmonary, ARDSexp) insult to the lung parenchyma [34]. ARDSp and ARDSexp are believed not identical in terms of anatomical-functional aspects, response to PEEP and recruitment maneuvers, prone position and other adjunctive therapies. Contradictory results have been reported in different clinical studies, questioning the reality of these two different syndromes [35]. Thus, heterogeneous ARDS patients are still considered to suffer from one syndrome, and are treated in the same way. We believe that understanding the range of different pathways that lead to pulmonary dysfunction makes it possible to target clinical treatment better. In recent years, a number of studies reported chest X-ray and CT differences between ARDSp and ARDSexp. Goodman et al. [36] studied 33 ARDS patients (22 ARDSp and 11 ARDSexp) by performing three representative scans at the apex (top of the upper aortic arch), at the hilum (first section below the carina), and at the base ( $2 \mathrm{~cm}$ above the highest diaphragm). The ventilatory setting was not standardized during scans. The lung was scored as follows: "normal lung," "ground-glass opacification" (mild increased attenuation with visible vessels), and "consolidation" (markedly increased attenuation with no visible vessels). They found that in ARDSexp, extent of ground-glass opacification was more than twofold greater than consolidation. In ARDSp, by contrast, there was an even balance between ground-glass opacification and consolidation. The patients with ARDSexp had $40 \%$ more ground-glass opacification than those with ARDSp. Conversely, the ARDSp patients had 50\% more consolidation than those with ARDSexp. The authors also found differences in the regional distribution of the densities. In ARDSexp ground-glass opacification was greater in the central (hilar) third of the lung than in the sternal or vertebral third. There was no significant craniocaudal predominance for ground-glass opacification or consolidation, but consolidation showed a preference for the vertebral position over the sternal and central positions. In ARDSexp groundglass opacification was evenly distributed in both the craniocaudal and sternal-vertebral directions. Consolidation tended to favour the middle and basal levels, but also favoured the vertebral position. The total lung disease was almost evenly distributed between the left and right lungs in both ARDSp and ARDSexp. However, grossly asymmetric disease was always due to asymmetric consolidation. Moreover, the presence of air bronchograms and pneumomediastinum were prevalent in ARDSp, while emphysema-like lesions (bullae) were comparable in both groups. Unfortunately, it appears that the word consolidation may have different meanings. For the radiologists, consolidation simply means a "marked increase in lung attenuation with no visible vessels," and may derive from alveolar atelectasis as well as alveolar filling. For the pathologists, consolidation refers only to alveolar filling.

D'Angelo et al. [37] reported homogeneous diffuse interstitial and alveolar infiltration, without evidence of atelectasis, in eight patients with ARDSp due to Pneumocystis carinii, whereas Winer-Muran et al. [38] found that dependent atelectasis were more common in patients with early ARDSexp compared to ARDSp. Desai et al. [39] reported a significantly higher incidence of intense parenchymal opacification in nondependent areas of the lung in patients with direct insult (indicative of consolidation secondary to inflammatory infiltrate), but no other differences emerged between the two groups. Moreover, the extent of intense parenchymal opacification in nondependent areas of the lung was inversely related to the time from intubation to CT. The authors concluded that differentiating between ARDSp and ARDSexp on the basis of CT findings is not straightforward, and that no single radiological feature is specifically associated with lung injury of either type.

Other observations were obtained by Rouby et al. [40] in 69 ARDS patients (49 ARDSp and 20 ARDSexp) in whom a whole lung CT scan was performed. CT densities were classified as consolidation or ground-glass opacification. Consolidation was defined as a homogeneous increase in pulmonary parenchymal attenuation that obscures the margins of the vessels and airway walls. Ground-glass opacities were defined as hazy, increased attenuation of the lung but with preservation of bronchiolar and vascular margins. A "lobar" pattern was defined as lung attenuation with a lobar or segmental distribution established on the recognition of anatomical structures such as the major fissure or the interlobular septa, a "diffuse" pattern as lung attenuation diffusely distributed throughout the lungs, and "patchy" pattern as lobar or segmental areas of lung attenuation in some parts of the lungs but lung attenuation without recognized anatomical limits in others. They found that ARDSp was more frequent among patients with diffuse and patchy attenuation, whereas ARDSexp was more common in patients with lobar attenuation.

In conclusion, CT findings support the hypothesis that the radiological pattern is different in ARDSp and ARDSexp. It should be kept in mind that these morphological observations have limitations. 


\section{CT SCAN AND THE VENTILATORY SETTINGS IN ARDS}

Treatment of ARDS includes specific action on the cause of ARDS, possible interventions in some of the molecular pathways leading to the widespread inflammation or coagulation abnormalities (steroids, activated protein $\mathrm{C}$ ), and, finally, supportive therapy, which primarily includes respiratory support and mechanical ventilation.

We believe that CT scanning is a primary tool to assess the ventilator-induced lung injury, and, more importantly, the most objective technique currently available to set mechanical ventilation from a relevant background.

\section{CT SCAN FOR SETTING THE TIDAL VOLUME}

Available evidence from large randomized controlled studies have shown better outcomes with routine use of low tidal volume (VT) [41]. The stress, i.e. the force expanding the lung, identified by the transpulmonary pressure and the strain, i.e. the ratio between the delivered VT and the endexpiratory lung volumes are major determinants of ventilator-induced lung injury [42]. Lung CT scan at endexpiration, at a low level of PEEP, allows quantification of the lung weight and the amount of nonaerated tissue as well as the amount of normally aerated, poorly aerated, and hyperinflated lung tissue. CT scan studies [3-5, 26] suggest that the lung tissue open to ventilation (poorly aerated plus normally aerated lung tissue) may range from $95 \%$ to $30 \%$ of the total lung weight. It has been proposed that VT should be titrated according to the ideal body weight (IBW) [43]. In fact, the hypothesis is that in normal subjects and different animal species there is a constant ratio between VT and the end-expiratory lung volume during spontaneous breathing in absence of PEEP. For example in humans, a VT of approximately 6 to $8 \mathrm{ml} / \mathrm{IBW}$ is delivered to a total endexpiratory lung volume of approximately 2000 to $3000 \mathrm{ml}$. The ratio between the $\mathrm{VT}$ and the end-expiratory lung volume, which represents the strain to the lung tissue, is approximately $500 \mathrm{ml} / 2500 \mathrm{ml}$, i.e. $1 / 5$. In ARDS, as discussed above, the end-expiratory lung volume is variable depending on the amount and severity of the diseased lung, and can vary from 100 to $1500 \mathrm{ml}$, on average. This implies that the same VT set according to the IBW may induce different degrees of strain [42, 44]. Furthermore, it has been hypothesized that despite VT and plateau pressure (Pplat) Pplat limitation, patients with a large non-aerated compartment are exposed to tidal hyperinflation in the normally aerated compartment. Terragni et al. [11] performed lung CT at end-expiration and end-inspiration in 30 ARDS patients ventilated with $6 \mathrm{ml} / \mathrm{kg}$ IBW VT. They found that tidal inflation largely occurred in the normally aerated compartment $(69.9 \pm 6.9 \%)$ in 20 patients but in the hyperinflated compartment $(63.0 \pm 12.7 \%)$ in the remaining 10. The lung of the former patients was defined as more protected and of the latter as less protected with respect to tidal hyperinflation occurrence. Between the more and the less protected patients, the non-aerated compartment was smaller and the normally aerated compartment larger in $(\mathrm{p}=$ $0.01)$, pulmonary cytokines were lower $(p<0.05)$, the ventilator-free days were $7 \pm 8$ and $1 \pm 2$ days $(\mathrm{p}=0.01)$, Pplat ranged between 25 and $26 \mathrm{cmH}_{2} \mathrm{O}$ and between 28 and $30 \mathrm{~cm} \mathrm{H}_{2} \mathrm{O}(\mathrm{p}=0.006)$. The authors concluded that limiting
VT to $6 \mathrm{ml} / \mathrm{kg}$ IBW and Pplat below $30 \mathrm{cmH}_{2} \mathrm{O}$ may not be sufficient to protect the lung in those patients exhibiting a large non-aerated compartment.

This issue has a major clinical relevance, because it is likely that CT scan can be useful to identify those patients who will require a further reduction in VT or Pplat or alternative ventilatory strategies like High Frequency Oscillation Ventilation or extracorporeal lung support. With High Frequency Oscillation Ventilation, extremely low VTs are delivered minimizing the stress and strain. With $\mathrm{CO}_{2}$ removal or extracorporeal oxygenation a further reduction of stress and strain can be expected from a reduction in VT. The extracorporeal lung support may be divided in two techniques: a) low flow techniques, mostly aiming at $\mathrm{CO}_{2}$ elimination, but not oxygenation improvement; b) high flow techniques, mostly aiming at both $\mathrm{CO}_{2}$ elimination and oxygenation improvement. The high flow extracorporeal lung support has been recently found effective to improve survival in ARDS patients [45]. Tidal hyperinflation may occur in patients with ARDS who are ventilated with VT of $6 \mathrm{ml} / \mathrm{kg}$ IBW develop Pplat between 28 and $30 \mathrm{cmH}_{2} \mathrm{O}$. In a recent paper, Terragni et al. [46] investigated whether VT lower than $6 \mathrm{ml} / \mathrm{kg}$ may enhance lung protection when respiratory acidosis is managed by extracorporeal $\mathrm{CO}_{2}$ removal in 32 ARDS patients. In patients with $28 \leq$ Pplat $\leq$ $30 \mathrm{~cm} \mathrm{H}_{2} \mathrm{O}$, VT was reduced from $6.3 \pm 0.2$ to $4.2 \pm 0.3$ $\mathrm{ml} / \mathrm{kg}$, and Pplat decreased from $29.1 \pm 1.2$ to $25.0 \pm 1.2$ $\mathrm{cmH}_{2} \mathrm{O}(\mathrm{P}<0.001)$. As a result, $\mathrm{PaCO}_{2}$ rose from $48.4 \pm 8.7$ to $73.6 \pm 11.1 \mathrm{mmHg}$ and $\mathrm{pH}$ declined from $7.36 \pm 0.03$ to $7.20 \pm 0.02(\mathrm{P}<0.001)$. Respiratory acidosis was managed by extracorporeal $\mathrm{CO}_{2}$ removal. Lung function, morphology, and pulmonary inflammatory cytokines were assessed at baseline and after $72 \mathrm{~h}$. The extracorporeal assist normalized $\mathrm{PaCO}_{2}(50.4 \pm 8.2 \mathrm{mmHg})$ and $\mathrm{pH}(7.32 \pm 0.03)$ and allowed $\mathrm{VT}<6 \mathrm{ml} / \mathrm{kg}$ for 144 hours (84-168). The improvement of morphological markers of lung protection and the reduction of pulmonary cytokines concentration $(\mathrm{P}<0.01)$ were observed after $72 \mathrm{~h}$ of ventilation with $\mathrm{VT}<6 \mathrm{ml} / \mathrm{kg}$. No complications were observed. They concluded VT $<6 \mathrm{ml} / \mathrm{Kg}$ enhanced lung protection. Respiratory acidosis resulting from low VT ventilation was safely and efficiently managed by extracorporeal $\mathrm{CO}_{2}$ removal.

In conclusion, CT scan could play a significant role in the future to select the optimal VT avoiding excessive stress and strain and to refer patients for extracorporeal lung support.

\section{CT SCAN FOR SETTING PEEP}

In the last years, several reports have dealt with recruitment/ PEEP selection [47] confirming that opening pressures are different across the lung parenchyma in ARDS, being the highest in the most dependent lung regions. Recent evidence suggested that high PEEP might provide clinical benefit in the subset of most severe patients as compared with low PEEP [41]. Indiscriminate application of recruitment maneuver in unselected ARDS does not provide any benefit. However, in the most severe patients, recruitment maneuver and high PEEP have to be considered.

Different methods may be used to detect potential of recruitment and, hence to optimize PEEP selection: a) static conditions in absence of PEEP or at fixed PEEP levels; b) physiologic response to different levels of PEEP. 


\section{Static Conditions in Absence of PEEP or at Fixed PEEP Levels}

We suggest analyzing: a) the chest X-ray; b) the Pressure-Volume curve and tidal compliance of the respiratory system; c) the level of oxygenation at PEEP 5 $\mathrm{cmH}_{2} \mathrm{O}$.

\section{Chest X-Ray}

Chest X-ray has been shown to provide important information to identify patients with low potential of recruitment. In fact, it has been clearly demonstrated that lobar densities on chest X-ray are associated with lobar densities in the dependent parts and relatively preserved aeration in the non dependent parts of the lung on CT scan in supine position. In these subjects the potential of recruitment is poor. Conversely, patchy infiltrates on chest X-ray may be equally characterized by lobar or patchy distribution of densities on CT scan. This suggests that patients with patchy chest X-ray may have a $50 \%$ probability to be low or high recruiters. Finally, diffuse densities on chest X-ray may be equally associated with lobar, patchy or diffuse densities at the CT scan. In this case patients have one third probability to be poor recruiters and two third to be recruiters. Lobar chest X-ray is able to identify those patients who are likely to be non recruiters $[10,13,40,48]$.

\section{The Pressure-Volume Curve}

The Pressure-Volume $(\mathrm{P} / \mathrm{V})$ curves of the respiratory system have been proposed to identify patients with higher potential of recruitment $[14,49]$. $\mathrm{P} / \mathrm{V}$ curves can be measured by static, with constant or sinusoidal flow methods and/or dynostatic methods for a breath-to-breath determination. With recent ventilators equipped with specific flow generators and software, $\mathrm{P} / \mathrm{V}$ curves can be obtained without disconnecting the patient from the ventilator. The inspiratory $\mathrm{P} / \mathrm{V}$ curve may be of help to identify patients with higher potential of recruitment (identification of inflection point and curvilinear $\mathrm{P} / \mathrm{V}$ curve) and those with a lower potential of recruitment (no inflection point and linear $\mathrm{P} / \mathrm{V}$ curve). It has been shown that in patients with curvilinear P/V curve, PEEP was associated with alveolar recruitment but not accompanied by lung overinflation. On the contrary, in patients with linear P/V curve, PEEP was associated with alveolar hyperinflation independently form the presence or not of substantial alveolar recruitment. However, the inspiratory $\mathrm{P} / \mathrm{V}$ curve does not provide useful informations about the specific values for setting optimal PEEP, but just gives a qualitative information. In fact PEEP is essentially an expiratory and not an inspiratory phenomenon. Thus, the presence of a deflection point on the expiratory $\mathrm{P}-\mathrm{V}$ curve may be of greater interest to set individual optimal PEEP.

\section{The $\mathrm{PaO}_{2} / \mathrm{FiO}_{2}$ Ratio at PEEP $5 \mathrm{~cm} \mathrm{H} \mathrm{H}_{2} \mathrm{O}$}

It has been shown that the oxygenation level at PEEP 5 $\mathrm{cmH}_{2} \mathrm{O}$ may identify patients with higher or lower potential of recruitment [10]. Oxygenation has been found to correlate with the amount of consolidated or recruitable non aerated tissue [50]. An oxygenation level lower than $150 \mathrm{mmHg}$ at $\mathrm{FIO}_{2} 100 \%$ on PEEP $5 \mathrm{~cm} \mathrm{H} \mathrm{H}_{2} \mathrm{O}$ may predict higher potential for recruitment. However, functional shunt poorly estimates the anatomical shunt compartment, due to the large variability in apparent perfusion ratio. Changes in anatomical shunt compartment with increasing PEEP, in each patient, may be estimated from changes in functional shunt, only if the anatomical-functional shunt relationship at $5 \mathrm{~cm} \mathrm{H}_{2} \mathrm{O}$ PEEP is known [51].

\section{Physiologic Response to Different Levels of PEEP}

Other methods to set optimal PEEP include a formal PEEP test. After having fully recruited the lungs, PEEP is progressively reduced and gas exchange, respiratory mechanics, and hemodynamics are recorded. Clinical data are controversial regarding the best physiological variable to be considered to set the optimal PEEP. We believe that, among others, the measurement of respiratory compliance may play a relevant role, being unaffected by altered distribution of regional perfusion and related only to the mechanical structure/function of the lung parenchyma $[15$, $52,53]$. However, to date no conclusive data are available in patients to indicate the best combination of different variables to be considered during a PEEP test.

\section{CT Scan at Different Pressure Levels}

CT scan may provide important informations to detect patients with high or low potential of recruitment, with the highest accuracy and precision. CT scan is the best available technique for studying lung collapse and refilling [20]. Lung recruitability has been evaluated in 68 ALI/ARDS from

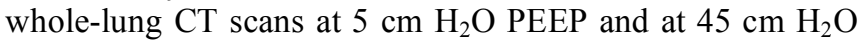
airway Pplat [10]. Lung recruitability was defined as the lung tissue regaining aeration from 5 to $45 \mathrm{~cm} \mathrm{H}_{2} \mathrm{O}$ airway pressure and was expressed as a percentage of the total lung weight. Moreover, to assess the effects of higher PEEP, a further $\mathrm{CT}$ scan of the whole lung at $15 \mathrm{~cm} \mathrm{H}_{2} \mathrm{O}$ PEEP was obtained. Physiologic variables were also recorded at 5 and $15 \mathrm{~cm} \mathrm{H}_{2} \mathrm{O}$ PEEP. The application of $15 \mathrm{~cm} \mathrm{H}_{2} \mathrm{O}$ PEEP was able to maintain recruited about $50 \%$ of the recruitable lung, independently on its absolute amount. Unexpectedly, lung recruitability was strictly associated with the overall severity of lung injury, as detected by CT scan and by physiologic variables. Similarly, lung recruitability closely correlated with mortality, this latter being higher in the highest recruiters. Of notice, the respiratory physiologic variables, particularly the changes in oxygenation, poorly predicted lung recruitability as assessed by CT scan. Furthermore, CT scan showed the large variability in the amount of lung recruitability and its strong association with the response to PEEP. Finally, CT scan cannot be taken over by simple techniques available at the bedside, such as variations in oxygenation or respiratory mechanics.

In conclusion, at present, there are no alternatives to CT scan to determine lung recruitability in a given patient, and it is quite evident that the assessment of the lung recruitability is necessary for optimal ventilatory setting.

\section{CT SCAN FOR DIAGNOSIS OF COMPLICATIONS OF MECHANICAL VENTILATION}

It is well recognized and widely documented that the use of CT scanning during ARDS may provide information that cannot be derived from the conventional anterior-posterior chest X-ray. Consequently, it has been shown that the information gained from $\mathrm{CT}$ scanning frequently affects patient clinical management $[54,55]$. In a retrospective 
review of 74 patients who had ARDS, CT scanning yielded additional information in $66 \%$ of the population and had a direct influence on treatment of 22\% [54]. Desai and Hansell [56] indicate that $\mathrm{CT}$ is best used to detect occult complications in patients who are deteriorating or not improving at the expected rate. Entities that can be detected more often in CT scans than in chest X-ray are: a) pneumonia localized behind the heart (Fig. 6); b) occult anterior, non dependent localized pneumothoraces (Fig. 7); c) lung abscesses; d) pleural effusions; e) lobar atelectasis; f) lung bullae.

In conclusion, we believe that one of the primary indications for CT scanning of patients who have ARDS is a sudden and unexplained deterioration of the clinical status or the lack of expected improvement. In these circumstances, an occult complication, when present, may be detected by CT scanning.

\section{CT SCAN EVOLUTION OVER TIME}

Data regarding the effects of duration of mechanical ventilation on lung structure of ARDS patients are astonishingly scanty [2]. The application of CT in ARDS

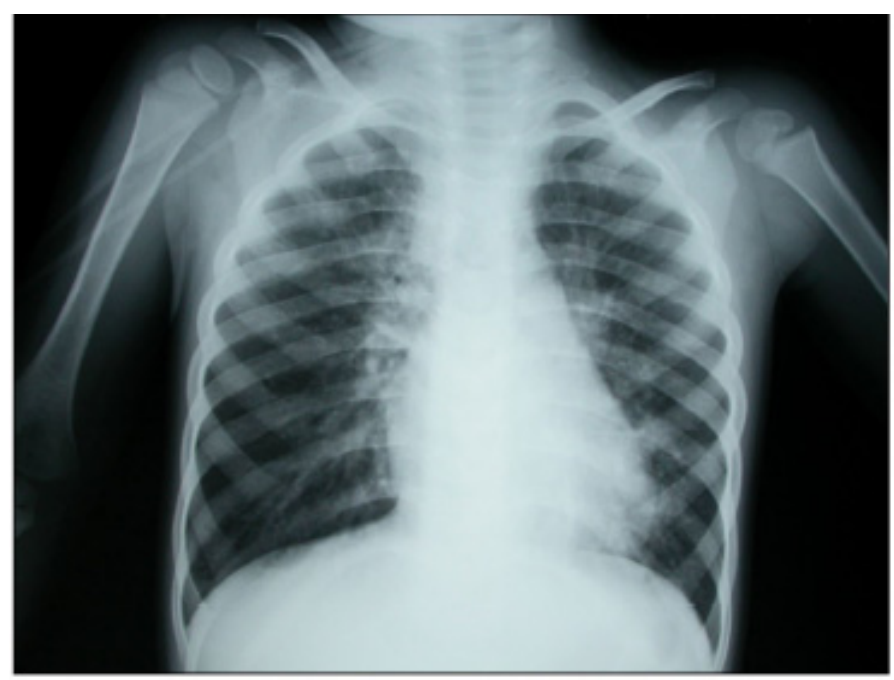

made it possible to detect in vivo the changes in lung morphology occurring during prolonged use of mechanical ventilation [57]. The most important finding is the presence of cysts and emphysema-like lesions prevalent in the dependent lung regions with the stage of disease and duration of mechanical ventilation. By contrast, the overall lung density decreases and becomes spread throughout the lung parenchyma instead of being prevalent in the most dependent part of the lung. In late ARDS, the emphysemalike lesions are associated with an increased incidence of pneumothorax as well as an increase in dead space and arterial carbon dioxide tension $\left(\mathrm{PaCO}_{2}\right)$. Moreover, in late ARDS the development of lung fibrosis reduces the transmission of hydrostatic forces with a consequent decrease in the occurrence of atelectasis in the dependent lung. A recent study showed that extensive thin-section CT abnormalities indicative of fibroproliferative changes were independently predictive of poor prognosis in patients with a clinically early stage of ARDS [58]. It is, thus, evident that the lung structure and function markedly change with the duration of mechanical ventilation. Consequently, it appears that the PEEP requirement in late ARDS is decreased, as

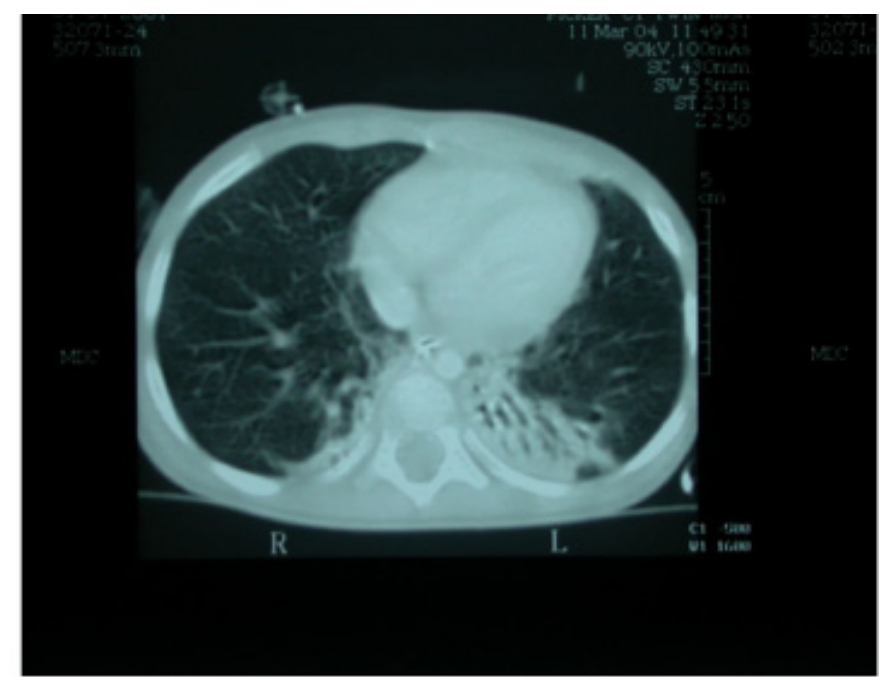

Fig. (6). Lung Aeration and Densities in ALI/ARDS: Chest X-Ray vs CT scan in a patient with retrocardiac pneumonia.
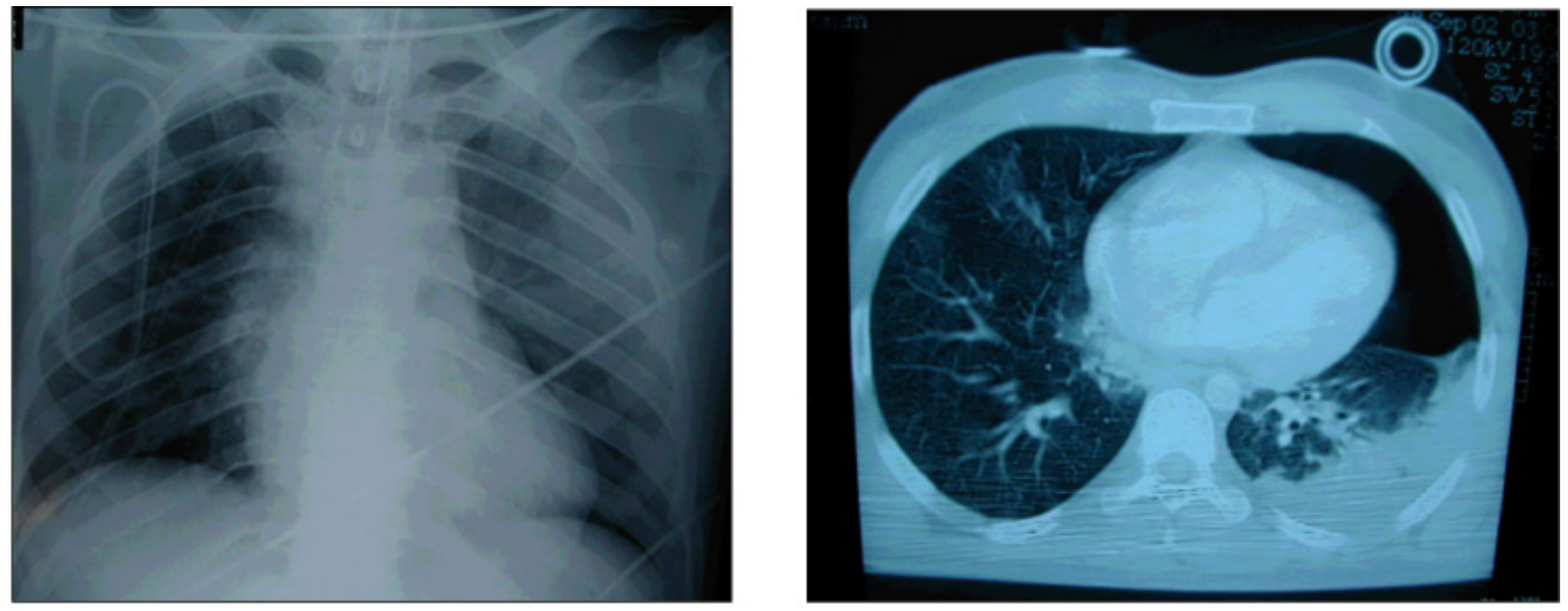

Fig. (7). Lung Aeration and Densities in ALI/ARDS: Chest X-Ray vs CT scan in a patient with anterior pneumothorax. 
compression atelectasis are no longer present in the late stage of the disease.

In conclusion, CT scan is an invaluable technique to follow the evolution with time of ARDS, allowing a better tailoring of ventilator management.

\section{CT SCAN IN ARDS: CLINICAL CLUES}

To conclude, we would like to make the following general recommendations to optimally perform CT scan in ARDS patients:

- Perform one single whole lung CT scan at endexpiration at PEEP $5 \mathrm{~cm} \mathrm{H}_{2} \mathrm{O}$ to evaluate the distribution of aeration and to compute the amount of lung weight. Only three lung CT slices (taken at the lung apex, hilum, and basis) may be sufficient for the assessment of lung recruitability (at PEEP $=5 \mathrm{~cm}$ $\mathrm{H}_{2} \mathrm{O}$ and at Pplat $=45 \mathrm{~cm} \mathrm{H}_{2} \mathrm{O}$ ). A recruitment maneuver to standardize for volume history should always be performed before CT scan. There is no specific recruitment maneuver recommended.

- $\quad$ Perform CT scan as early as possible after onset of ARDS (if clinical characteristics persist for more than 24 hours) and repeat the CT scan after 1 week if no clinical improvement.

- Perform a CT scan in presence of any clinical deterioration not explained by conventional diagnostic tools.

- Consider the measurement of extravascular lung water and end-expiratory lung volume by non radiological techniques and lung ultrasound if $\mathrm{CT}$ scan cannot be done.

\section{REFERENCES}

[1] Pelosi P, Crotti S, Brazzi L, Gattinoni L. Computed tomography in adult respiratory distress syndrome: what has it taught us? Eur Respir J 1996; 9: 1055-62.

[2] Gattinoni L, Caironi P, Pelosi P, Goodman LR. What has computed tomography taught us about the acute respiratory distress syndrome? Am J Respir Crit Care Med 2001; 164: 1701-11.

[3] Rouby JJ, Puybasset L, Nieszkowska A, Lu Q. Acute respiratory distress syndrome: lessons from computed tomography of the whole lung. Crit Care Med 2003; 31: S285-95.

[4] Caironi P, Carlesso E, Gattinoni L. Radiological imaging in acute lung injury and acute respiratory distress syndrome. Semin Respir Crit Care Med 2006; 27: 404-15.

[5] Gattinoni L, Caironi P, Valenza F, Carlesso E. The role of CT-scan studies for the diagnosis and therapy of acute respiratory distress syndrome. Clin Chest Med 2006; 27: 559-70.

[6] Kollef MH, Schuster DP. The acute respiratory distress syndrome. N Engl J Med 1995; 332: 27-37.

[7] Ware LB, Matthay MA. The acute respiratory distress syndrome. N Engl J Med 2000; 342: 1334-49.

[8] Phua J, Badia JR, Adhikari NKJ, et al. Has mortality from acute respiratory distress syndrome decreased over time? Am J Respir Crit Care Med 2009; 179: 220-7.

[9] Reske AW, Busse H, Amato $\mathrm{MB}$, et al. Image reconstruction affects computer tomographic assessment of lung hyperinflation. Intensive Care Med 2008; 34: 2044-53.

[10] Gattinoni L, Caironi P, Cressoni M, et al. Lung recruitment in patients with the acute respiratory distress syndrome. N Engl J Med 2006; 354: 1775-86.
[11] Terragni PP, Rosboch G, Tealdi A, et al. Tidal hyperinflation during low tidal volume ventilation in acute respiratory distress syndrome. Am J Respir Crit Care Med 2007; 175: 160-6.

[12] Gama de Abreu M, Spieth P, Pelosi P, et al. Noisy pressure support ventilation: A pilot study on a new assisted ventilation mode in experimental lung injury. Crit Care Med 2008; 36: 818-27.

[13] Puybasset L, Gusman P, Muller JC, Cluzel P, Coriat P, Rouby JJ. Regional distribution of gas and tissue in acute respiratory distress syndrome. III. Consequences for the effects of positive endexpiratory pressure. CT Scan ARDS Study Group. Adult Respiratory Distress Syndrome. Intensive Care Med 2000; 26: 1215-27.

[14] Rouby JJ, Lu Q, Vieira S. Pressure/volume curves and lung computed tomography in acute respiratory distress syndrome. Eur Respir J Suppl 2003; 42: 27-36.

[15] Carvalho AR, Spieth PM, Pelosi P, et al. Ability of dynamic airway pressure curve profile and elastance for positive endexpiratory pressure titration. Intensive Care Med 2008; 34: 2291-9.

[16] Schiller HJ, McCann UG, Carney DE, Gatto LA, Steinberg JM, Nieman GF. Altered alveolar mechanics in the acutely injured lung. Crit Care Med 2001; 29: 1049-55.

[17] Malbouisson LM, Muller JC, Constantin JM, et al. Computed tomography assessment of positive end-expiratory pressureinduced alveolar recruitment in patients with acute respiratory distress syndrome. Am J Respir Crit Care Med 2001; 163: 1444-50.

[18] Griffey RT, Sodickson A. Cumulative radiation exposure and cancer risk estimates in emergency department patients undergoing repeat or multiple CT. Am J Roentnol 2009; 192: 887-92.

[19] Gattinoni L, Presenti A, Torresin A, et al. Adult respiratory distress syndrome profiles by computed tomography. J Thorac Imaging 1986; 1: 25-30.

[20] Gattinoni L, Pelosi P, Crotti S, Valenza F. Effects of positive endexpiratory pressure on regional distribution of tidal volume and recruitment in adult respiratory distress syndrome. Am J Respir Crit Care Med 1995; 151: 1807-14.

[21] Gattinoni L, Pelosi P, Vitale G, Pesenti A, D'Andrea L, Mascheroni D. Body position changes redistribute lung computed-tomographic density in patients with acute respiratory failure. Anesthesiology 1991; 74: 15-23.

[22] Lu Q, Malbouisson L, Mourgeon E, Goldstein I, Coriat P, Rouby JJ. Assessment of PEEP-induced reopening of collapsed lung regions in acute lung injury: are one or three CT sections representative of the entire lung? Intensive Care Med 2001; 27: 1504-10.

[23] Zinserling J, Wrigge H, Neumann $\mathrm{P}$, et al. Methodologic aspects of attenuation distributions from static and dynamic thoracic CT techniques in experimental acute lung injury. Chest 2005; 28: 2963-70.

[24] Markstaller K, Eberle B, Kauczor HU, et al. Temporal dynamics of lung aeration determined by dynamic CT in a porcine model of ARDS. Br J Anaesth 2001; 87: 459-68.

[25] Markstaller K, Karmrodt J, Doebrich M, et al. Dynamic computed tomography: a novel technique to study lung aeration and atelectasis formation during experimental CPR. Resuscitation 2002; 53: 307-13.

[26] Rouby JJ, Constantin JM, Roberto De A Girardi C, Zhang M, Lu Q. Mechanical ventilation in patients with acute respiratory distress syndrome. Anesthesiology 2004; 101: 228-34.

[27] Ashbaugh DG, Boyd Bigelow D, Petty TL, Levine BE. Acute respiratory distress in adults. Lancet 1967; 2: 319-23.

[28] Bernard GR, Artigas A, Brigham KL, et al. The AmericanEuropean Consensus Conference on ARDS. Definitions, mechanisms, relevant outcomes, and clinical trial coordination. Am J Respir Crit Care Med 1994; 149: 818-24.

[29] Ferguson ND, Davis AM, Slutsky AS, Stewart TE. Development of a clinical definition for acute respiratory distress syndrome using the Delphi technique. J Crit Care 2005; 20: 147-54.

[30] Murray JF, Matthay MA, Luce JM, Flick MR. An expanded definition of the adult respiratory distress syndrome. Am Rev Respir Dis 1988;138: 720-3. 
[31] Villar J, Pérez-Méndez L, López J, et al. An early PEEP/FIO2 trial identifies different degrees of lung injury in patients with acute respiratory distress syndrome. Am J Respir Crit Care Med 2008;176: 795-804.

[32] Ferguson ND, Frutos-Vivar F, Esteban A, et al. Acute respiratory distress syndrome: underrecognition by clinicians and diagnostic accuracy of three clinical definitions. Crit Care Med 2005; 33: 2228-34.

[33] Caironi P, Langer T, Gattinoni L. Acute lung injury/acute respiratory distress syndrome pathophysiology: what we have learned from computed tomography scanning. Curr Opin Crit Care 2008; 14: 64-9.

[34] Rocco PRM, Pelosi P. Pulmonary and extrapulmonary acute respiratory distress syndrome: myth or reality? Curr Opin Crit Care Med 2008; 14: 50-5.

[35] Rouby JJ. Recruitment in pulmonary and extrapulmonary acute respiratory distress syndrome: the end of a myth. Anesthesiology 2007; 106: 203-4.

[36] Goodman LR, Fumagalli R, Tagliabue P, et al. Adult respiratory distress syndrome due to pulmonary and extrapulmonary causes: CT, clinical, and functional correlation. Radiology 1999; 213: 54552.

[37] D'Angelo E, Calderini E, Robatto FM, Puccio P, Milic-Emili J. Lung and chest wall mechanics in patients with acquired immunodeficiency syndrome and severe Pneumocystis carinii pneumonia. Eur Respir J 1997; 10: 2343-50.

[38] Winer-Muram HT, Steiner RM, Gurney JW, et al. Ventilatorassociated pneumonia in patients with adult respiratory distress syndrome: CT evaluation. Radiology 1998; 208: 193-9.

[39] Desai SR, Wells AU, Suntharalingam G, Rubens MB, Evans TW, Hansell DM. Acute respiratory distress syndrome caused by pulmonary and extrapulmonary injury: a comparative CT study. Radiology 2001; 218: 689-93.

[40] Rouby JJ, Puybasset L, Cluzel P, Richecoeur J, Lu Q, Grenier P. Regional distribution of gas and tissue in acute respiratory distress syndrome. II: Physiological correlations and definition of an ARDS severity score. Intesive Care Med 2000; 26: 1046-56.

[41] Putensen C, Theuerkauf N, Zinserling J, Wrigge H, Pelosi P. Metaanalysis: ventilation strategies and outcomes of the acute respiratory distress syndrome and acute lung injury. Ann Intern Med 2009; 151: 566-76.

[42] Caironi P, Cressoni M, Chiumello D, et al. Lung opening and closing during ventilation of acute respiratory distress syndrome. Am J Respir Crit Care Med 2010; 181: 578-86.

[43] The Acute Respiratory Distress Syndrome Network. Ventilation with lower tidal volumes as compared with traditional tidal volumes for acute lung injury and the acute respiratory distress syndrome. N Engl J Med 2000; 342: 1301-8.
[44] Chiumello D, Carlesso E, Cadringher P, et al. Lung stress and strain during mechanical ventilation for acute respiratory distress syndrome. Am J Respir Crit Care Med 2008; 178: 346-55.

[45] Peek GJ, Mugford M, Tiruvoipati R, et al. Efficacy and economic assessment of conventional ventilatory support versus extracorporeal membrane oxygenation for severe adult respiratory failure (CESAR): a multicentre randomised controlled trial. Lancet 2009; 374: 1351-61.

[46] Terragni PP, Del Sorbo L, Mascia L, et al. Tidal volume lower than $6 \mathrm{ml} / \mathrm{kg}$ enhances lung protection: role of extracorporeal carbon dioxide removal. Anesthesiology 2009; 111: 826-35.

[47] Gattinoni L, Carlesso E, Brazzi L, Caironi P. Positive endexpiratory pressure. Curr Opin Crit Care 2010; 16: 39-44.

[48] Puybasset L, Cluzel P, Gusman P, et al. Regional distribution of gas and tissue in acute respiratory distress syndrome. I. Consequences for lung morphology. Intensive Care Med 2000; 26: 857-69.

[49] Gattinoni L, Pesenti A, Avalli L, Rossi F, Bombino M. Pressurevolume curve of total respiratory system in acute respiratory failure. Computed tomographic scan study. Am Rev Respir Dis 1987; 136: 730-6.

[50] Gattinoni L, Pesenti A, Bombino M, et al. Relationships between lung computed tomography density, gas exchange, and PEEP in acute respiratory failure. Anesthesiology 1988; 69: 824-32.

[51] Cressoni M, Caironi P, Polli F, et al. Anatomical and functional intrapulmonary shunt in acute respiratory distress syndrome. Crit Care Med 2008; 36: 669-75.

[52] Carvalho AR, Jandre FC, Pino AV, et al. Positive end-expiratory pressure at minimal respiratory elastance represents the best compromise between mechanical stress and lung aeration in oleic acid induced lung injury. Crit Care 2007; 11: R86.

[53] Suarez-Sipmann F, Böhm SH, Tusman G, et al. Use of dynamic compliance for open lung positive end-expiratory pressure titration in an experimental study. Crit Care Med 2007; 35: 214-21.

[54] Tagliabue M, Casella TC, Zincone GE. CT and chest radiography in the evaluation of adult respiratory distress syndrome. Acta Radiol 1994; 35: 230-4.

[55] Goodman LR. Congestive heart failure and adult respiratory distress syndrome. New insights using computed tomography. Radiol Clin North Am 1996; 34: 33-46.

[56] Desai SR, Hansell DM. Lung imaging in the adult respiratory distress syndrome: current practice and new insights. Intensive Care Med 1997; 93: 7-15.

[57] Gattinoni L, Bombino M, Pelosi P, et al. Lung structure and function in different stages of severe adult respiratory distress syndrome. JAMA 1994; 271: 1772-9.

[58] Ichikado K, Suga M, Muranka H, et al. Prediction of prognosis for acute respiratory distress syndrome with thin-section CT: validation in 44 cases. Radiology 2006; 238: 321-9.

Received: December 22, 2009

Revised: January 5, 2010

Accepted: January 5, 2010

(C) Pelosi and de Abreu; Licensee Bentham Open.

This is an open access article licensed under the terms of the Creative Commons Attribution Non-Commercial License (http: //creativecommons.org/licenses/by-nc/ 3.0/) which permits unrestricted, non-commercial use, distribution and reproduction in any medium, provided the work is properly cited. 